6 Mitra, A.P., and Ramanamurthy, Y. V., Radlo $S c i ., 7,67-72$ (1972).

7 Campbell, W. H., Matsushita, S., and Bunder, B. K., Radio Sci., 6, 165-170 (1971)

8 Campbell, W. H., Planet. Space Sci., 20,61-71 (1972)

9 Murthy, A. V.S., and Yacob, A., Planet. Space. Sci., 22, 1583-1584 (1974).

I5s-61 1968 .

1 Sastri, H. J., and Murthy, B. S., Solar Phys. (in the press).

13 Volland, H., and Taubenheim, J., J.atmos.terr. Phys., 12, 258 (1958)

. Veldkamps, J., and Van Sabben, D., J.atmos. terr. Phys., 18, 192 (1960).

14 Pinter, S., Bull. astr. Insts Col., 18, 274-281 (1967).

\section{Ghost echoes on the Earth-Moon path}

ON July 7, 1974 while using a Moon Bounce technique on $1,296 \mathrm{MHz}$ I observed the appearance of strange, delayed echoes. My equipment consists of a parabolic antenna 26 feet in diameter with a circularly polarised feed horn driven with $500-\mathrm{W}$ continuous wave from a transmitter. The receiver has a noise figure of $2 \mathrm{~dB}$ and a bandpass of 500 cycles and the equipment had a very distinct note because of a spurious frequency near the fundamental; on the Moon-Earth circuit it is very easy to identify this signal because of this unique characteristic. On the day in question a series of dots or a single dash were being reflected back from the Moon after $2.6 \mathrm{~s}$. Suddenly there appeared a second signal delayed by approximately $2 \mathrm{~s}$. This signal had the same characteristics of the Moon Bounce signal except that it was weaker.

At the time of the observations it was afternoon, the Sun was almost due west and the Moon was to the south-west with an altitude of about $30^{\circ}$. Throughout a series of transmissions the returning Moon signal was followed about $2 \mathrm{~s}$ later by the delayed ghost signal with the same characteristic note of the transmitter. Unfortunately, I could not record the signals though they continued for $20 \mathrm{~min}$. When I failed to track the Moon with my antenna, the Moon signal would fade but the echo remained at about the same strength.

The following day a severe radio blackout occurred, and lasted for several days, coincidentally with the appearance of a large sunspot. Relating my reception of the ghost echo with this violent solar eruption I suggest that the large streamer of gas from the corona of the Sun produced a highly ionised cloud which reflected the radio signals I had directed towards the Moon. If this streamer approached with a speed of $1,000 \mathrm{~km}$ $\mathrm{s}^{-1}$, with a front like a shock wave, it could have acted as a good reflector. The cloud would have been about $800,000 \mathrm{~km}$ out in space, as indicated from the delay times of 4-5 s.

\section{Hans Lohmann Rasmussen}

\section{Amateur Radio OZ9CR,} Asum Odense Denmark

Received February 11; accepted July 16, 1975.

\section{${ }^{22} \mathrm{Na}, \mathrm{Ne}-\mathrm{E}$, extinct radioactive anomalies and unsupported ${ }^{40} \mathrm{Ar}$}

A NEW picture ${ }^{1}$ of the origin of the known extinct radioactivities ( ${ }^{129} \mathrm{I}$ and ${ }^{244} \mathrm{Pu}$ ) holds that these radioactive species were precipitated in grains forming in the rapidly cooling ejecta of explosive nucleosynthesis, and that their decay occurred in interstellar grains rather than in the meteorites. If so, our interpretation of extinct radioactivities is enlarged. Their detectability is no longer related to the usual criterion that they live long enough for the meteorites to form, but rather that they live long enough for grains to form in the expanding envelope.

My first point is to interpret ${ }^{22} \mathrm{Na}$ as a detectable extinct radioactivity. Its half life $(2.6 \mathrm{yr})$ seems long enough for an expanding gas to cool to the point of grain formation. If we take the adiabatic relationship $\rho / T^{3}=$ constant for purposes of a simple estimate, we find that matter having a density of
$10^{4} \mathrm{~g} \mathrm{~cm}^{-3}$ at $T=10^{9} \mathrm{~K}$ has a density of $10^{-14} \mathrm{~g} \mathrm{~cm}^{-3}$ when $T=10^{3} \mathrm{~K}$ where grains can form copiously. The observations ${ }^{2}$ of Nova Serpentis 1970 confirm very extensive grain formation in similar circumstances on a time scale of a few days. If the expansion speed of a supernova envelope is $10^{4} \mathrm{~km} \mathrm{~s}^{-1}$, this drop in density requires about 3 yr. Condensation temperatures may be reached even earlier if the expansion is not adiabatic, but also radiates.

The ejection of ${ }^{22} \mathrm{Na}$ in large amounts is expected from the helium shells of explosive supernovae ${ }^{3}$ and from the surface explosions of novae $e^{4}$ both at the level $10^{-3} \mathrm{~g} \mathrm{~g}^{-1}$. I have studied these for their prospects for nuclear gamma-ray astronomy, but since ${ }^{22} \mathrm{Na}$ may in part be expected to precipitate in grains before it decays, we may also expect the existence of interstellar grains being isotopically rich in ${ }^{22} \mathrm{Ne}$ in comparison with the Sun. The admixing of these grains without vaporisation into the forming carbonaceous chondrites is a good candidate for the source of the ${ }^{22} \mathrm{Ne}$-rich neon component $\mathrm{Ne}-\mathrm{E}$, which was discussed by Black ${ }^{5}$, who attributed it to an extrasolar source. It is at least as ${ }^{22} \mathrm{Ne}$-rich as ${ }^{20} \mathrm{Ne} /{ }^{22} \mathrm{Ne} \lesssim 3.4$, and could conceivably be pure ${ }^{22} \mathrm{Ne}$. The fact that the released gas is purest in $\mathrm{Ne}-\mathrm{E}$ around $1,000{ }^{\circ} \mathrm{C}$ in stepwise heating probably refiects the fact that ${ }^{22} \mathrm{Ne}_{\mathrm{E}}$ occupies a refractory ${ }^{22} \mathrm{Na}$ site in the grains. The absolute amounts of ${ }^{22} \mathrm{Ne}_{\mathrm{E}}$ are also relatively constant near $10^{-8} \mathrm{~cm}^{8} \mathrm{~g}^{-1}$ STP, suggesting uniform sprinkling of presolar grains through $\mathrm{Cl}$ chondrites.

The ${ }^{22} \mathrm{Na}$ yield is more than adequate to account for the $\mathrm{Ne}-\mathrm{E}$ anomaly. Nucleosynthesis calculations suggest, but do not prove, that the fraction of all ${ }^{22} \mathrm{Ne}$ that was synthesised as ${ }^{22} \mathrm{Na}$, in specific ejecta concentrations near $10^{-3} \mathrm{~g}^{-1} \mathrm{~g}$ (refs 3,4 ), is about $10^{-2}$, which is also about $5 \times 10^{-2}$ of the total stable ${ }^{23} \mathrm{Na}$ abundance. This total nucleosynthesis yield is quite large, and about one-tenth of it is here supposed to be incorporated into grains before the ${ }^{22} \mathrm{Na}$ decay. I have argued ${ }^{1}$ that the fraction $f_{\mathrm{Na}}$ of condensed solar system $\mathrm{Na}$ that existed as unvaporised presolar grains lies between $10^{-1}$ and $10^{-2}$. If these estimates are correct, the concentration of $\mathrm{Ne}-\mathrm{E}$ potentially available if neon gas were not lost from grains is between $5 \times 10^{-4}$ and $5 \times 10^{-5}$ of stable $\mathrm{Na}$. That this is many orders of magnitude greater than observed Ne-E concentrations reflects the loss of daughter neon from the hot but unvaporised grains.

A correlation of $\mathrm{Ne}-\mathrm{E}$ with $\mathrm{Na}$ concentration would not necessarily be expected, however, because these same explosively ejected zones are not rich in stable ${ }^{23} \mathrm{Na}$. This $\mathrm{Ne}-\mathrm{E}$ is a component of $\mathrm{Ne}-\mathrm{A}$ (ref. 5), which shares a "threshold-forappearance" effect with $\mathrm{He}-\mathrm{A}$, which is deficient in ${ }^{3} \mathrm{He}$ in comparison with the solar wind. Component $\mathbf{A}$ is interpreted by Black $^{5}$ as a linear combination of $E$ and a component $D$, which he interprets as a primitive solar wind, before the deuterium has burned to ${ }^{3} \mathrm{He}$. In the framework of the present discussion, we see that $\mathrm{D}$ may also contain the dense gas surrounding the newly formed grains in the expanding supernova. I suggest interpreting $E$ as ${ }^{22} \mathrm{Ne}$ from ${ }^{22} \mathrm{Na}$ decay and essentially pure ${ }^{4} \mathrm{He}$ from the helium shell in which the ${ }^{22} \mathrm{Na}$ is synthesised ${ }^{3}$. Other isotopes of neon, especially ${ }^{21} \mathrm{Ne}$, also exist in the gas, but $\left({ }^{4} \mathrm{He} / \mathrm{Ne}\right)_{\mathrm{gas}} \approx 10^{4}$ so that ${ }^{4} \mathrm{He}$ should be the dominant trapped gas. Only if neon is trapped more efficiently than helium in this environment will the newly synthesised neon gas contribute a component to $\mathrm{E}$ as well. Calculations of this neon synthesis have been published ${ }^{8,7}$. Arnould and Beelen ${ }^{7}$ noted the similarity to Ne-E of special cases of the total gas yield, but the ${ }^{22} \mathrm{Na}$ interpretation seems more plausible since it is much more easily trapped than neon gas.

Black $^{5}$ also calls attention to the fact that in the $\mathrm{C} 2$ chondrite Nagoya the dark gas-rich phases contain 3 times as much ${ }^{40} \mathrm{Ar}$ as the light gas-poor phases, although the light phases have a higher fraction of $\mathrm{Ne}-\mathrm{E}$ in their total neon. Perhaps the explanation is that the dark phases contain a higher fraction of presolar grains. The ${ }^{40} \mathrm{~K} /{ }^{41} \mathrm{~K}$ ratio was initially much higher in nucleosynthesis events, so grains forming there rather than in the solar system would now have more ${ }^{40} \mathrm{Ar} /{ }^{41} \mathrm{~K}$. This suggestion is not necessarily inconsistent with the bulk ${ }^{20} \mathrm{Ne} /{ }^{22} \mathrm{Ne}$ 